
Pathophysiology of Haemostasis and Thrombosis

\title{
To General Haemostasis - the Evidence-Based Route
}

\author{
Elisabeth Erhardtsen \\ Novo Nordisk A/S, Bagsvaerd, Denmark
}

\section{Key Words}

Inhibitors · Thrombin - Safety · Traumata · Anticoagulant therapy $\cdot$ Impaired liver function

\begin{abstract}
Recombinant factor VIla (rFVIla) was developed for the treatment of bleeding in haemophilia patients with inhibitors and has also been used successfully in non-haemophilia patients with acquired antibodies against FVIII (acquired haemophilia). Based on dose-finding trials and a compassionate-use programme, rFVIla was approved for use in haemophilia patients with inhibitors in 1996. At pharmacological doses, rFVIla has been found to enhance thrombin generation on already activated platelets. Therefore, it is likely that rFVIla will also be beneficial in providing haemostasis in other situations characterised by profuse bleedings and an impaired thrombin generation. Patients with thrombocytopenia have a decreased number of platelets and thus an impaired thrombin generation. A reduction in bleeding time was reported in approximately $50 \%$ of patients with thrombocytopenia and a prolonged bleeding time who participated in a trial of rFVIla. Moreover, in 8 patients with 9 overt bleeds who were involved in the study, bleeding stopped in 7 episodes after rFVIla administration. Case reports on the haemostatic effect of rFVIla in thrombocytopenia have also been published. Reports have also
\end{abstract}

been published on the successful use of rFVIla in patients with platelet function deficiencies such as Glanzmann's thrombasthenia and Bernard-Soulier syndrome. A number of haemostatic changes occur after extensive trauma, surgery and bleeding, all of which potentially contribute to an impaired thrombin generation. The effect of rFVIla has been demonstrated in a number of patients after trauma and bleeds and upper gastrointestinal bleeding episodes. Reports on the beneficial use of rFVIla in liver transplantation have also been published. Several randomised blinded studies are now underway in e.g. hepatectomy, upper gastrointestinal bleedings, transplantations and intra-cerebral bleeds. In summary, rFVIla may be an effective and safe method to induce haemostasis in patients within areas of coagulation factor deficiency or platelet disorders and the ongoing and planned randomised studies may lead the way to the use of rFVIla in general haemostasis.

Copyright $\odot 2002$ S. Karger AG, Basel

\section{Introduction}

Recombinant activated coagulation factor VII (rFVIIa) was developed for treatment of bleeding in haemophilia patients with inhibitors (HI) and has also been shown to be effective in the treatment of patients with acquired antibodies against FVIII (acquired haemophil-

\begin{tabular}{ll}
\hline KARGER & ( ) 2002 S. Karger AG, Basel \\
Fax +41 61306 1234 & 1424-8832/02/0327-0047\$18.50/0 \\
$\begin{array}{l}\text { E-Mail karger@karger.ch } \\
\text { www.karger.com }\end{array}$ & $\begin{array}{l}\text { Accessible online at: } \\
\text { www.karger.com/journals/pht }\end{array}$
\end{tabular}

Elisabeth Erhardtsen

International Medical Director Haemostasis

Novo Nordisk A/S, 53a Krogshojvej

DK-2880 Bagsvaerd (Denmark)

Tel. +45 4442 8888, Fax +45 4442 1213, E-Mail eer@novonordisk.com 
ia). When administered in pharmacological doses rFVIIa enhances thrombin generation on the activated platelets. Patients with a variety of coagulation abnormalities characterized by uncontrollable bleedings and an impaired thrombin generation may benefit from rFVIIa in providing haemostasis. Clinical experience is available from a few patients with thrombocytopenia $[1,2]$ and other platelet defects and from patients with an impaired liver function $[3,4]$.

\section{Clinical Experience with rFVlla in Haemophilia Patients with Inhibitors}

Administration of FVIII or FIX concentrates does not induce hemostasis in haemophilia patients who have developed inhibitors against FVIII or FIX as the factor concentrates are inhibited by the antibodies in the patient. rFVIIa has proven to be a safe and efficient agent for the treatment of bleeding episodes in HI patients and up to now, October 2001, more than 230,339 standard doses have been given.

Elective surgery has previously been contraindicated in HI patients who are at high risk of uncontrollable bleeding. However, major orthopaedic surgery such as hip or knee replacement has been successfully performed under the cover of rFVIIa in a number of HI patients [58]. The recommended dose was $90-120 \mu \mathrm{g} / \mathrm{kg}$ rFVIIa administered every $2 \mathrm{~h}$ during the first $24 \mathrm{~h}$ depending on the type of surgery and the clinical response. Furthermore, rFVIIa has been given in connection with minor surgery and dental surgery with success [8].

A prospective, double-blind, randomized trial comparing two doses of rFVIIa (35 and $90 \mu \mathrm{g} / \mathrm{kg}$ ) in HI patients undergoing surgery was published in 1998 [9]. Bolus injections of rFVIIa were given every 2 nd hour for the first $48 \mathrm{~h}$ and the same dose was then given every 2-6 $\mathrm{h}$ for an additional 3 days. Major surgical procedures such as synovectomies, hip arthroplasties, knee joint replacement were included. A statistically significant difference in efficacy favouring the high-dose group was observed from day 3 to day 5 with regard to maintained hemostasis, number of days of dosing required and in the number of injections. Based on the results from this study, the investigators concluded that rFVIIa appears to be an efficacious first-line agent in surgery in HI patients, and the $90 \mu \mathrm{g} / \mathrm{kg}$ dose was more effective for both minor and major procedures [9].

Since 1988 rFVIIa has been given in a compassionate use protocol to HI patients suffering from serious bleed- ings in whom all other therapies had failed. Essentially the same dose schedule as recommended in surgery was used. The overall effective response after 8 and $24 \mathrm{~h}$ in the first 55 consecutive bleeds was $91 \%$ and $90 \%$, respectively [10].

84 patients were treated with two rFVIIa dosages ( 35 and $70 \mu \mathrm{g} / \mathrm{kg}$ ) in a randomized, double-blind, multicentre trial including 179 joint, muscle, and mucocutaneous bleeding episodes [11]. A delay before start of treatment (8.4-10.0 h) may have contributed to the fact that there was no significant difference in efficacy between the two groups although a trend in both groups towards a better outcome for joint bleeds treated within $6 \mathrm{~h}$ was observed.

A home treatment study with rFVIIa was performed to optimize the treatment with rFVIIa in HI patients and make it more similar to that of haemophilia patients without inhibitors [12]. By using a dose of $90 \mu \mathrm{g} / \mathrm{kg}$ at 3-hour intervals in mild-to-moderate bleeding episodes an average of 2.3 doses were required to prevent the development of full joint or muscle bleeds [12].

\section{Safety}

In 664 patients (primarily HI patients) enrolled in Novo Nordisk-sponsored clinical trials, thrombotic events were reported in $4 \mathrm{HI}$ patients and in 3 patients with acquired haemophilia (AH) (fig. 1).

An 8-year-old boy with HI developed signs of a left occipital infarct following a complicated course of subdural haematoma. A thrombotic complication related to the use of rFVIIa could not be excluded; however the investigator stated that an alternative explanation might have been ischemia due to pressure on the supplying vessel related to the mass effect of the haematoma.

A 4-year-old boy with HI developed a thrombosis in the right jugular vein two days following the insertion of a central venous catheter subsequent administration of rFVIIa.

A 36-year-old male with $\mathrm{HI}$ was treated initially with aPCC, and then with rFVIIa due to a large haematoma. Thirteen days later the patient experienced a massive gastrointestinal bleeding secondary to stress ulcer. The next day he developed abdominal pain, and a laparotomy revealed necrotic large bowel requiring resection, no evidence of thrombosis. The patient died nine days after surgery. The autopsy showed patent mesenteric vessels and a review of the colon pathology showed extensive gangrenous necrosis in several sections, but the mesenteric vessels were all patent.
48
Pathophysiol Haemost Thromb 2002;32(suppl 1):47-52
Erhardtsen 
Fig. 1. Thrombotic complications reported in haemophilia trials.

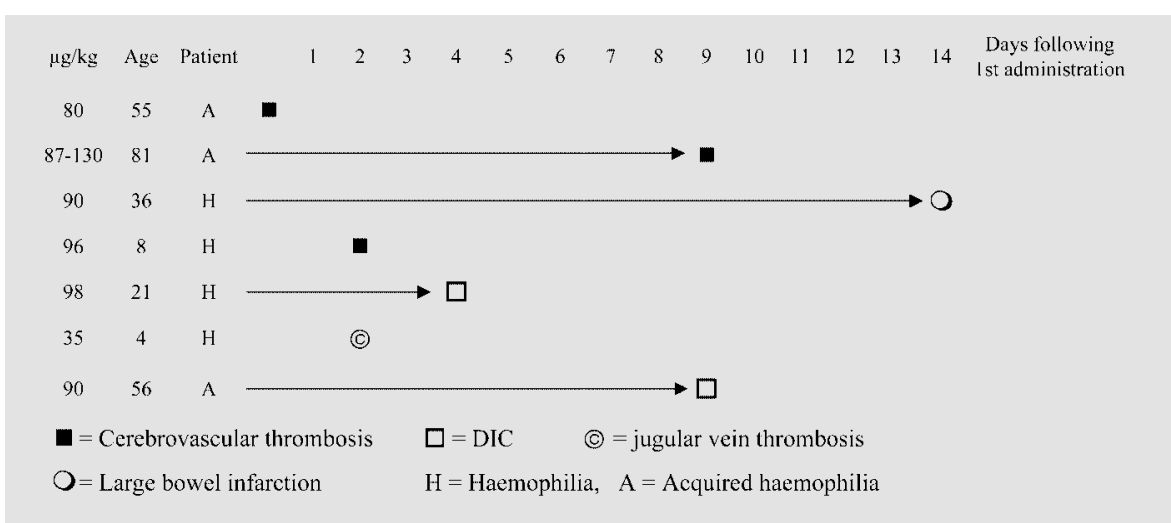

A 21-year-old male with $\mathrm{HI}$ underwent extensive surgery twice for a large hip abscess. During the surgery extensive myonecrosis and necrotized fasciitis from knee to pelvis were noted. During the second surgery necessitated by extensive profuse bleeding, the patient experienced cardiac arrest refractory to resuscitation. An autopsy revealed microscopic microthrombi in the pulmonary vasculature.

The AH patients who were reported to have thrombotic events were multi-transfused patients. One, a 81-yearold male who was treated due to gastrointestinal bleeding had a DVT reported after infusion of porcine FVIII, human FVIII and rFVIIa. Another, a 55-year-old male who was treated for massive hepatic and subcapsular haemorrhage had an infarct reported after infusion of Feiba, Autoplex and rFVIIa. The third case was a 56-year-old female who had a lab DIC reported after infusion of blood transfusions and rFVIIa.

Recombinant FVIIa has been shown to induce hemostasis in severe HI patients both in major surgery [9], in serious bleedings in patients in whom all other therapies had failed [10], in joint and muscle bleeds [11], and in the home-treatment setting [12]. The complication of thrombotic events after treatment with rFVIIa seems to be rare and in most cases alternative aetiology was present (multitransfusion, sepsis, etc.).

\section{Recombinant FVIla in Patients with an Impaired Thrombin Generation Other than Haemophilia}

Patients with a decreased number of platelets have been shown to have a decreased thrombin formation [13]. In vitro studies have proven that the addition of rFVIIa in concentrations of 50-500 $\mathrm{n} M$ can cause a dose-dependent increase in the initial rate of thrombin generation and a shortening of the lag phase of platelet activation [14]. A study in 74 thrombocytopenic patients showed a shortening of the bleeding time in approximately $50 \%$ of the patients and in 8 thrombocytopenic patients rFVIIa had an effect on an open bleeding (nosebleed, vaginal bleed, oozing from catheters etc). The bleeding either stopped or slowed down (6/8 stopped; $2 / 8$ slowed down) following administration of rFVIIa. Even in patients with a platelet count below 10,000 the bleeding stopped following the administration of $100 \mu \mathrm{g} / \mathrm{kg}$ of rFVIIa [15].

Furthermore, a case report on a hemostatic effect of rFVIIa in a thrombocytopenic patient has been published [16]. This patient had platelet counts below 5,000 indicating that rFVIIa has a hemostatic effect also in the presence of very low platelet counts.

\section{Safety}

No thrombotic events were reported in this population.

Preliminary studies including a few case reports indicate that rFVIIa may be of use in treating bleedings in patients with thrombocytopenia and platelet functional defects. Controlled trials are required for definitive proof of concept.

\section{Severe Traumata Resulting in Profuse Bleeding}

Other situations with a potential defective thrombin generation include patients who have been through severe traumata resulting in profuse bleeding requiring multiple transfusions of various blood products. Acute trauma in humans has been shown to initiate a number of hemostatic changes [13, 17]. A haemostatic effect has been demon- 
strated after administration of rFVIIa in a limited number of patients after trauma and bleedings [18-20].

The first patient with extensive bleedings following an intra-abdominal gunshot treated successfully with rFVIIa was published in 1999 [20]. This patient bled at a rate of $300 \mathrm{ml} / \mathrm{min}$ in spite of extensive transfusion therapy including packed red cells (5 1), fresh frozen plasma (3 1), platelets (20 units), cryoprecipitate (10 units) and antifibrinolytic therapy. In a desperate attempt to control the bleeding rFVIIa in a dose of $60 \mu \mathrm{g} / \mathrm{kg}$ was given leading to a decrease in rate of bleeding to $10-15 \mathrm{ml} / \mathrm{min}$. Slow oozing from all wound surfaces continued, however, but stopped after a second dose of rFVIIa $(60 \mu \mathrm{g} / \mathrm{kg})$ given $1 \mathrm{~h}$ after the first one enabling surgical repair. The patient's condition remained stable, and no further blood loss occurred. Following this experience 9 more critically-ill, coagulopathic, multi-transfused trauma patients in whom conventional surgical and medical hemostatic treatment modalities had failed were treated with rFVIIa [19]. All patients suffered from uncontrolled bleeding despite surgical efforts and massive replacement therapy. Doses of rFVIIa were in the range of $40-120 \mu \mathrm{g} / \mathrm{kg}$. Four of the patients received more than one dose (2-3). Blood requirements decreased considerably after rFVIIa. A median of 2 (range: 1-2.75) doses were required. Three patients expired - one suffered profound shock, hypothermia and acidosis for $14 \mathrm{~h}$ prior to administration of rFVIIa and died towards the end of surgery, two other patients died 4 weeks after treatment with rFVIIa from sepsis and liver failure related to the extensive liver hypoxia. Another case report on the successful use of rFVIIa in a woman experiencing heavy bleedings after stab wounds was published [18].

\section{Safety}

No thrombotic events were reported in any of the above mentioned patients.

The experience with rFVIIa in trauma patients experiencing excessive bleeding is based on case reports and indicates a hemostatic effect of rFVIIa administered in doses of $60-120 \mu \mathrm{g} / \mathrm{kg}$. Controlled studies are needed to prove the beneficial effect of rFVIIa in these patients.

\section{Defective Synthesis of FVII}

A defect in the normal synthesis of FVII is reported in patients receiving oral anticoagulant therapy and in patients with impaired liver function. 2002;32(suppl 1):47-52

\footnotetext{
$\overline{50} \quad \overline{\text { Pathophysiol Haemost Thromb }}$
}

\section{Patients Receiving Oral Anticoagulant Therapy}

FVII has been shown to be the earliest and the most sensitive of the coagulation factors to be affected by the oral anticoagulant therapy. Spontaneous haemorrhages represent a major treatment complication and have been reported to occur in around $10 \%$ of patients receiving oral anticoagulant therapy $[21,22]$. These patients may also require reversal of their prolonged INR when invasive procedures are scheduled.

In a randomized, double-blind, placebo-controlled study, 28 healthy volunteers were administered acenocoumarol twice daily in order to boost INR values to within therapeutic levels. At INR values $>2.0$, levels of FVII were $4-17 \%$ [23]. Following the administration of one dose of rFVIIa ranged between 5 and $320 \mu \mathrm{g} / \mathrm{kg}$ the INR was normalized. Following doses of $>120 \mu \mathrm{g} / \mathrm{kg}$ the INR remained normalized for $12 \mathrm{~h}$. No signs of systemic activation of the coagulation system were seen.

One spontaneous nosebleed in a patient on warfarin with an INR of 2.9 has been reported successfully treated with two doses of $80 \mu \mathrm{g} / \mathrm{kg}$ rFVIIa [24]. Another report describes the use of rFVIIa in 7 adult patients who all had critically prolonged INR (range 3.2-13.9), 3 of whom required surgery. The doses administered ranged from 20 to $90 \mu \mathrm{g} / \mathrm{kg}$ and all patients were reported to have a positive outcome [25]. These observations indicate that rFVIIa may be used to reverse the effect of warfarin or other vitamin $\mathrm{K}$ antagonist therapy in cases where administration of vitamin $\mathrm{K}$ alone has been found insufficient. However, further studies are required to establish the optimal dose.

\section{Patients with Impaired Liver Function}

The liver is the principal site for synthesis and clearance of coagulation factors, components of the fibrinolytic system, and naturally occurring anticoagulants. The haematological abnormalities most frequently seen in cirrhotic patients include thrombocytopenia, a prolonged PT, and hyperfibrinolysis [26]. Cirrhotic patients do not generally experience bleeding episodes apart from upper GI bleeding but they are at an increased risk of bleeding from routine procedures such as liver biopsy, and also during major surgery such as liver transplantation [27].

Resulting from their complex coagulation pattern these patients may have an impaired thrombin generation and administration of rFVIIa in high doses may be able to compensate for the lack of the different coagulation
Erhardtsen 
parameters. A haemostatic effect has been proven in a limited number of liver disease patients [3, 4]. rFVIIa has also been evaluated in clinical trials with liver diseased patients. Ten cirrhotic patients whose PT did not correct to within $2 \mathrm{~s}$ above the control reference value were given three successive dosages of rFVIIa $(5,20,80 \mu \mathrm{g} / \mathrm{kg})$ during a 3-week period in a randomized study [28]. The PT transiently corrected to normal in all three dosage groups and the length of the effect was dose related.

A blind randomized study included 65 cirrhotic patients undergoing laparoscopic biopsy under the cover of $\mathrm{rFVIIa}$ in a dose range of $5-120 \mu \mathrm{g} / \mathrm{kg}$ [29]. Thirteen of the patients received a rescue dose of $80 \mu \mathrm{g} / \mathrm{kg}$ of rFVIIa. None required operative intervention or transfusion for blood loss after performing the biopsy and no clinically significant post-treatment changes in other coagulation parameters were observed. The authors concluded that the results suggest that laparoscopic liver biopsy can be performed safely and reliably using rFVIIa in patients in whom the standard procedure might be contraindicated due to coagulopathy.

\section{Safety}

Two thrombotic events were reported in the above mentioned patients. A 38-year-old male was undergoing laparoscopic liver biopsy. Six days after the administration of rFVIIa a routine Doppler ultrasound examination suggested thrombosis of the main portal vein. Eleven days after the administration of rFVIIa, the patient was admitted with peritoneal sepsis secondary to cirrhosis. The patient expired on day 13. The autopsy showed diffuse thrombosis of the portal vein system and massive alchemic hepatocellular necrosis. The microscopic examination revealed an overall pattern of acute thrombosis superimposed on pre-existing organizing thrombi.

A 43-year-old female with no prior history of liver disease was transferred to hepatology service with acute liver failure secondary to the use of Duract (bromfenac) for arthritis/club foot (approximately 5-6 months usage). The patient was treated with rFVIIa and subsequently underwent laparoscopic liver biopsy. Post-biopsy the patient's haematocrit dropped (from 34.3 to 28.5). The platelet counts also declined (from 129,000 to 119,000). No bleeding source was identified. No fibrinogen or PT values are available. The liver biopsy revealed $60-80 \%$ necrosis and the patient was referred to and successfully underwent liver transplantation.

Preliminary data seem to indicate that rFVIIa has effect in liver-diseased patients; however, controlled studies are required to prove the haemostatic effect and safety of rFVIIa in liver-diseased patients undergoing surgery or experiencing a spontaneous bleeding.

\section{Building Strong Evidence}

In vitro data conclude that rFVIIa can increase thrombin formation in different situations in which thrombin formation is insufficient. This is further substantiated by case stories and preliminary studies which indicate that rFVIIa may be able to control bleeding in different situations. A number of studies are under way in order to collect data from randomised placebo-controlled studies. These will focus on patients with liver disease undergoing surgery or experiencing spontaneous bleeding, patients with thrombocytopenia experiencing bleeding, patients with intracerebral haemorrhage, and patients with trauma.

\section{Conclusion}

Recombinant FVIIa is approved for treatment of haemophilia patients with inhibitors, and data on safety and efficacy of rFVIIa in the treatment of bleeding patients outside the haemophilia area are accumulating.

\section{Acknowledgement}

I thank Susan Eriksen for secretarial assistance. 


\section{References}

1 Kristensen J, Killander A, Hippe E, Helleberg C, Ellegaard J, Holm M, Hedner U: Recombinant factor VIIa (rFVIIa) reduces the bleeding time in patients with thrombocytopenia. Abstract presented at the 35th Annual Meeting of ASH, St. Louis, December 3-7, 1993.

2 Poon MC, Demers C, Jobin F, Wu JWY: Recombinant factor VIIa is effective for bleeding and surgery in patients with Glanzmann thrombasthenia. Blood 1999;94:3951-3953.

3 Chuansumrit A, Treepongkaruna S, Phuapradit P: Successful invasive procedures in children with liver failure using recombinant factor VIIa. Haemophilia 2000;6:348.

4 Papatheodoridis GV, Chung S, Keshav S, Hardaker L, Pasi J, Burroughs AK: Recombinant factor VIIa is used in a Jehova's Witness with liver cirrhosis to correct prothrombin time, bleeding time, and thromboelastographic parameters, enabling safe percutaneous injection of hepatocellular carcinoma. Abstract presented at ISTH 1999.

5 Hedner U, Glazer S, Pingel K, Alberts KA, Blombäck M, Schulman S, Johnsson H: Successful use of recombinant factor Viia in patient with severe haemophilia A during synivectomy. Lancet 1988;ii:1193.

6 Hedner U, Ingerslev J: Clinical use of recombinant FVIIa (rFVIIa). Transfus Sci 1998;19: 163-176.

7 Ingerslev J, Freidman D, Gastineau D, Gilchrist G, Johnsson H, Lucas G, McPherson J, Preston E, Scheibel E, Shuman M: Major surgery in haemophilic patients with inhibitors using recombinant factor VIIa. Haemostasis 1996;26(suppl 1):118-123.

8 Lusher JM, Ingerslev J, Roberts HR, Hedner $\mathrm{U}$ : Clinical experience with recombinant factor VIIa. Blood Coagul Fibrinolysis 1998;9:119_ 128.

9 Shapiro AD, Gilchrist GS, Hoots WK, Cooper HA, Gastineau DA: Prospective, randomised trial of two doses of rFVIIa (NovoSeven) in haemophilia patients with inhibitors undergoing surgery. Thromb Haemost 1998;80:773778.

10 Glazer S, Hedner U, Falch JF: Clinical update on the use of recombinant factor VII. Adv Exp Med Biol 1995;386:163-174.
11 Lusher JM, Roberts HR, Davignon G, Joist JH, Smith H, Shapiro A, Laurian Y, Kasper CK, Mannucci PM: A randomized, doubleblind comparison of two dosage levels of recombinant factor VIIa in the treatment of joint, muscle and mucocutaneous haemorrhages in persons with haemophilia $\mathrm{A}$ and $\mathrm{B}$, with and without inhibitors. rFVIIa Study Group. Haemophilia 1998;4:790-798.

12 Key NS, Aledort LM, Beardsley D, Cooper HA, Davignon G, Ewenstein BM, Gilchrist GS, Gill JC, Glader B, Hoots WK, Kisker CT, Lusher JM, Rosenfield CG, Shapiro AD, Smith H, Taft E: Home treatment of mild to moderate bleeding episodes using recombinant factor VIIa (NovoSeven) in haemophiliacs with inhibitors. Thromb Haemost 1998;80:912-918.

13 Hedner U, Erhardtsen E: Potential role for rFVIIa in transfusion medicine. Transfusion 2001; in press.

14 Kjalke M, Monroe DM, Hoffman M, Roberts HR, Hedner U, Ezban M: High-dose factor VIIa restores platelet activation and total thrombin generation in a model system mimicking hemophilia A or B conditions. Blood 1999;94(suppl 1):451a.

15 Kristensen J, Killander A, Hippe E, Helleberg C, Ellegaard J, Holm J, Kutti J, Mellqvist U-H, Johansson JE, Glazer S, Hedner U: Clinical Experience with recombinant factor VIIa in patients with thrombocytopenia. Haemostasis 1996;26(suppl 1):159-164.

16 Vidarsson B, Ônundarson P: Recombinant factor VIIa for bleeding in refractory thrombocytopenia. Thromb Haemost 2001;83:634-635.

17 Attar S, Boyd D, Layne E, McLaughlin J, Mansberger AR, Cowley RA: Alterations in coagulation and fibrinolytic mechanisms in acute trauma. J Trauma 1969;9:939-965.

18 Essex D, Bluth M, Gloster E, Dimaio T, O’Neill P, Waly D, Kurtz R, Strauss R: Successful use of recombinant factor VIIa (rFVIIa) for trauma-associated massive hemorrhage. Blood 2000;96:268a.
9 Martinowitz U, Kenet G, Onaca N, Luboshitz J, Amit J, Heim M: New treatment of uncontrolled hemorrhage in trauma/surgical patients: Induction of local hypercoagulation. Abstract presented at the 60th Annual Meeting of the American Association for the Surgery of Trauma, San Antonio, USA, October 2000.

20 Kenet G, Walden R, Eldad A, Martinowitz U: Tratment of traumatic bleeding with recombinant factor VIIa. Lancet 1999;354:1879.

21 Kearon C, Hirsh J: Management of anticoagulation before and after elective surgery. $\mathrm{N}$ Engl J Med 1997;336:1506-1511.

22 Gitter MJ, Jaeger TM, Petterson TM, Gersh BJ, Silverstein MD: Bleeding and thromboembolism during anticoagulant therapy: A population-based study in Rochester, Minnesota. Mayo Clin Proc 1995;70:725-733.

23 Erhardtsen E, Nony $\mathrm{P}$, Dechavanne $\mathrm{M}$, Ffrench P, Boissel JP, Hedner U: The effect of recombinant factor VIIa (NovoSeven(TM)) in healthy volunteers receiving acenocoumarol to an International Normalized Ratio above 2.0. Blood Coagul Fibrinolysis 1998;9:741-748.

24 Berntorp E, Stigendal L, Lethagen S, Olofsson L, Hedner U: NovoSeven (R) in warfarintreated patients. Blood Coagul Fibrinolysis 2000;11:S113-S115.

25 Deveras RAE, Kessler CM: Recombinant factor VIIa (rFVIIa) successfully and rapidly corrects the excessively high international normalized ratios (INR) and prothrombin times induced by warfarin. Blood 2000;96:638a.

26 Paramo JA, Rocha E: Hemostasis in advanced liver disease. Semin Thromb Hemost 1993;19. 84-190.

27 Rapaport SI: Coagulation problems in liver disease. Blood Coagul Fibrinolysis 2000;11:S69S74.

28 Bernstein DE, Jeffers L, Erhardtsen E, Reddy KR, Glazer S, Squiban P, Bech R, Hedner U, Schiff ER: Recombinant factor VIIa corrects prothrombin time in cirrhotic patients: A preliminary study. Gastroenterology 1997;113: 1930-1937.

29 Jeffers L, Balart L, Erhardtsen E, Chalasani N, Ortiz A, Pyrsopoulos N: Efficacy and safety of rFVIIa in patients with severe coagulopathy undergoing laparoscopic liver biopsy. Blood 1999;94(suppl 1):236a. 